\title{
Rahamim: a criação como dor de parto e graça originária
}

Rahamin: the creation as childbirth pain and original grace

Recebido: 21/02/2017. Aprovado: 17/03/2017.

\section{Luiz Carlos Susin*}

Resumo: O presente artigo pretende explorar o sentido radical da misericórdia com a compreensão do universo enquanto criação em seus diferentes níveis e linguagens - mundo, terra e céus, ambientes ecológicos, etc. - através de uma incursão de caráter fenomenológico na tradição bíblica, centrando-se no capítulo oitavo da Carta aos Romanos. Assim, depois da constatação do sofrimento do mundo, entre misericórdia entendida biblicamente e ecologia assim como hoje é compreendida encontra nexos que juntam contemplação, ação, graça, esperança e paciência.

Palavras-chave: Criação. Cuidado. Graça originária.

Abstract: This article aims to explore the radical sense of mercy and the comprehension of the universe as creation in its different levels and languages - world, earth and skies, environments, etc. - through a phenomenological incursion in the biblical tradition, focusing on the chapter eight of the Letter to the Romans. Thus, after verifying the suffering in the world, between the biblically defined mercy and the ecology as we understand it today, we can find meanings that join contemplation, action, grace, hope and patience.

Keywords: Creation. Care. Original grace.

* Doutor em Teologia pela Pontifícia Universidade Gregoriana, Roma, Itália. Professor de Teologia na Pontifícia Universidade Católica do Rio Grande do Sul e na Escola Superior de Teologia e Espiritualidade Franciscana, Porto Alegre, RS. Secretário Geral do Fórum Mundial de Teologia e Libertação. Ex-membro da equipe de redação da revista Concilium. Membro fundador e ex-presidente da Associação de Teologia e Ciências da Religião (SOTER).

E-mail: Icsusin@pucrs.br 


\section{Introdução}

Como se relaciona a misericórdia com a criação divina e a dimensão ecológica da criação? A pergunta é também: como se faz uma impostação da dimensão ecológica da misericórdia? Não é muito difícil se utilizarmos o capítulo de Paulo que está anunciado como $O$ mistério da "criação em dores de parto" (Rm 8,18-25). Quando se diz que a criação está em "dores de parto", ela está exatamente naquela condição em que, em hebraico, se expressa com a palavra rahamim: misericórdia. Logo, há aí alguma coisa de profundo que pode ser muito estimulante. Ainda que se traduza normalmente por misericórdia ou compaixão, às vezes piedade, a palavra comum é misericórdia. Ela provém de rehem, que significa útero, e que, no plural, indica as contrações e dores para dar à luz; é a dor da vida. Normalmente a dor é ameaça de morte; e há um risco também na dor de parto, mas é uma dor para vida. É isso que nós vamos procurar tratar aqui.

Antes de nos localizarmos no capítulo oitavo da Carta aos Romanos, onde está esse texto, vamos examinar todo o contexto. Mas em primeiro lugar vamos passear por um contexto atual mais amplo e paradigmático: quando Abraão contemplava o céu, as estrelas, ele contemplava, de alguma forma, o futuro, uma promessa de futuro. Olhando para as mesmas estrelas, no entanto, Galileu olhava não mais o futuro, mas o passado (e isso é rigorosamente científico: a luz que chega até a Terra já partiu talvez milhões de anos-luz do nosso passado e está chegando agora; e é até possível que aquela estrela já esteja apagada, já não exista). Mas a questão principal não é só a diferença de olhar: como é que um olha o futuro e outro olha o passado? Não é só uma diferença de paradigma, de modelos, mas é, sobretudo, diferença de conhecimento: são duas formas de conhecimento, duas formas que permanecem. Pois podemos olhar com o olhar da ciência - e nós estamos, nesses 500 anos de modernidade, nos habituando cada vez mais a ter um olhar que vê tudo através da ótica da ciência. Então é o olhar de Abraão que está com problema, porque de alguma forma a ciência veio desencantando o mundo e por isso nós temos uma visão desencantada também das estrelas depois dos últimos séculos: elas não falam de promessa, de futuro, mas basicamente de passado. Embora agora a própria ciência já modifique bastante este olhar reducionista, e já esteja inclusive nos ajudando a termos um novo olhar. Desde que podemos ter a foto do globo todo da terra tomada de fora da terra, pela primeira vez a nossa geração é aquela que pode ver a nossa casa realmente com um olhar desde fora, desde longe, e pode vê-la na sua totalidade. Para todas 
as outras gerações antes de nós não era dada essa possibilidade. Mas olhar a terra desde fora também é uma superação da forma de conceber a terra e o universo segundo um padrão cartesiano, mecanicista, que foi a visão da modernidade. Uma visão bíblica, abraâmica, que durou cristianismo adento até o Renascimento, era uma cosmovisão aberta entre céus e terra; anjos não eram novidades por se atravessarem por aí, o céu estava aberto para a terra e a terra para o céu, essa era a narrativa. A modernidade proibiu àquilo que está no céu aparecer na terra. Por isso Nossa Senhora é tão teimosa justamente na modernidade: é como um "tapa de luva”, de protesto.

Conta-se nos Fioretti de São Francisco que um grupo de frades, indo com o santo para Compostela em peregrinação, encontrou no meio do caminho um doente. Segundo a forma de vida deles, era necessário cuidar do doente, e então delegaram Frei Bernardo, o primeiro companheiro de Francisco para que ficasse e tomasse conta do doente enquanto os demais prosseguiriam. Uma vez curado o doente, Bernardo se colocou com toda pressa no caminho para alcançar os demais. E deu com um rio, ficando perturbado com a dificuldade de passá-lo. Ele, definitivamente, não sabia mais como atravessar. Então um anjo apareceu, pegou Bernardo, atravessou-o e ele ficou feliz e encantado, não porque o anjo apareceu, mas porque ele fez o favor de levá-lo para o outro lado. É que aparecer não era nem problema e nem novidade, o milagre consistia somente em ter atravessado o rio e tornado possível o impossível. Dando um salto no tempo: na narrativa de Fátima, o sol gira maravilhosamente para provar que Nossa Senhora apareceu. Está exatamente invertido: o sol, ao contrário do rio de Bernardo na Idade Média, foi um espetáculo para provar a possibilidade do impossível, que é o fato mesmo do aparecimento em si. Esta inversão é muito sintomática: Maria não aparece para fazer o sol girar, como o anjo apareceu a Bernardo para atravessar o rio, mas o sol gira para dizer para todo mundo que ela apareceu ali em Fátima. Isto se deve a esta ruptura no olhar que nós tínhamos com maior naturalidade antes. É importante darmo-nos conta deste problema. O mundo não é mais uma criação aberta à criatividade contínua da parte do além, de um criador, mas é um mundo imanente, sistema fechado, exatamente o contrário do que analisou Alexandre Koyré em Do mundo fechado ao universo infinito. ${ }^{1} \mathrm{Na}$ verdade, é um mundo modelado pela técnica, pela tecnociência, pela produção e consumo.

1 KOYRÉ, Alexandre. Do mundo fechado ao universo infinito. Rio de Janeiro; São Paulo: Forense Universitária; Edusp, 1979. 


\section{Um mundo doente: fim de um mundo?}

Alguns problemas ecológicos podem ser mais bem compreendidos a partir do novo modelo. São colocados a partir de um pensador do grupo de estudos do Edgar Morin, um pesquisador e economista francês, Patrick Viveret. ${ }^{2} \mathrm{O}$ mundo concebido e percebido assim como ele veio sendo tratado nesses últimos séculos, produz na superfície cada vez mais crises financeiras, com ciclos cada vez mais rápidos. Isto é ainda superfície, porque estamos dentro de um sistema que devemos voltar a chamar de sistema capitalista. Elas são produzidas atualmente por bolhas especulativas. É que nossa economia se tornou cada vez mais especulativa. A economia real não está à altura da economia especulativa, e isso vai produzindo cada vez mais bolhas e por isso mais crises. E agora temos um acúmulo de paraísos financeiros, que têm sempre limite por se tornarem cada vez mais virtuais, e um retorno a uma apropriação do real, a partir do financeiro é complicado e arriscado, mas afinal acaba sendo necessário. Seria interessante analisar não só a migração dos "abutres", mas também a apropriação que ultimamente se vêm fazendo na área da realidade econômica, por exemplo da terra, da água. Segundo os dados apresentados por diversas ONGs reunidas no Fórum Social Mundial de Montreal, nós tivemos ultimamente, apesar do crescimento da consciência do drama ecológico, uma exacerbação assustadora de extrativismo seja mineral, seja de fontes de energias, de petróleo, de madeira, como aumento exponencial de monoculturas. Essa situação faz com que algumas empresas tenham mais terra, mais propriedade real, não só papéis, economia financeira, em países da África como o Congo, rico em minerais, do que países inteiros da Europa.

O segundo nível é a crise ecológica como tal; e essa crise ecológica tem esses nomes: aquecimento global, desertificação de certas áreas, elevação do nível dos mares, que já ameaça o desaparecimento de algumas áreas de ilhas do pacífico. Há a chamada pegada ecológica, o custo ecológico da nossa existência. A era do antropoceno, esta era de domínio do ser humano sobre o planeta, dá sinais de que o ser humano, quer dizer, nossa ação humana, realmente influencia a totalidade do Planeta Terra. A previsão é de que a migração climática vai se acentuar e, em última análise, vai haver intensificação da desigualdade. Há possibilidade de

2 Cf. VIVERET Patrick. Sobre o bom uso do fim de um mundo. In: SUSIN, Luiz Carlos; SANTOS, Joe Marçal Gonçalves dos. Nosso planeta, nossa vida. Ecologia e Teologia. São Paulo: Paulinas, 2011. p. 25-39. 
agravamento súbito se houver, como já se está discutindo, uma aceleração da calefação, do derretimento das geleiras e elevação dos mares.

O terceiro nível afetará desesperadamente nossas bocas com a fome. É a crise alimentar, não só de segurança alimentar, mas, de fato, a carência, o que pode tocar no risco do caos social. Os sinais e as estatísticas são desalentadores: ainda que tecnicamente haja possibilidade de segurança alimentar, as estatísticas mostram a sua degradação. Inclusive nas populações animais, nas abelhas, borboletas, estes seres mais sensíveis ao ambiente, na dificuldade de se nutrirem os animais de reservas e florestas. Mas nos Andes e na África as populações que já lutavam com a aspereza do solo e do clima para cavar seu alimento agora têm dificuldades aumentadas. E isso são sinais.

E o quarto nível de crise, o último analisado por Viveret, é o nível humano como tal, o nível civilizatório, que gera as perguntas: "o que nós fizemos de errado? Isto teria que ter sido necessariamente assim? Nós poderíamos andar a contracorrente deste caminho? Temos condições de fazer uma curvatura para outra direção?" Isto é o que nós precisamos nos perguntar, afinal de contas. Estas perguntas se aprofundam em questões que recuperam a metafísica: Qual é o sentido de viver sobre a terra? Que significa ser humano? Estas questões que atingem o que chamamos de civilização da história da humanidade estão no fundo de tudo isto.

\section{Há remédios novos e antigos}

Estes são os problemas básicos, seguindo a exposição de Viveret. Precisamos nos dar conta também de que a modernidade não produziu simplesmente problemas; ela produziu lutas e revoluções cada vez em ciclos mais intensos, e produziu de modo especial os direitos humanos. Em termos de direitos humanos bastaria voltarmos para trás talvez 50 anos e já nos daríamos conta de que fizemos alguns progressos. Reparemos também que a modernidade foi tomando alguma distância da legitimação religiosa e metafísica: ela se autolegitima. Esta é uma discussão filosófica: se ela pode se dar fundamento para si mesma, se ela pode autolegitimar-se, mas esta é a tendência, o caminho é a busca de cada vez maior autonomia. Assim, o poder não vem mais de Deus, vem do povo. Desde Napoleão, quando tomou a coroa das mãos do papa e se colocou para si mesmo. uma ruptura simbólica! E assim nas outras áreas: a economia não é mais economia da salvação, agora a salvação se dá pela economia. E acontece que os direitos humanos entraram nesse clima. Mesmo que se possa traçar o seu caminho 
saído da religião, agora a relação é invertida: os direitos humanos julgam as religiões. Porém, na verdade, os direitos humanos são uma conquista da modernidade graças à fermentação crítica dos valores evangélicos. A herança desses valores passa pela cultura da cristandade e produz a fina flor dos direitos humanos. Porém agora a relação está invertida, como dissemos acima: se a religião, na melhor forma de compreender, produziu os direitos humanos, hoje são os direitos humanos que fazem a crítica da religião, dos comportamentos religiosos. Por exemplo, quando uma atitude bíblica fundamentalista defende uma postura racista ou homofóbica ou xenofóbica, os direitos humanos vão "botar o dedo na moleira" dessa postura religiosa; em palavras mais populares, hoje são os direitos humanos que estão de olho na religião. E são os direitos humanos que nos mostram se conseguimos manter um nível civilizatório de humanidade: quando eles funcionam razoavelmente.

Há, porém, valores que são anteriores à modernidade, e nós precisamos ter um critério hermenêutico e exegético para abordá-los e recuperar o olhar de Abraão, olhar que via nas estrelas a promessa de um futuro. É uma maneira "sacramental" de olhar o universo, onde existe uma linguagem simbólica, numa poética narrativa, mas não um simbolismo sem consequências. No sacramento o símbolo é eficaz. A definição mais curta de sacramento foi lapidada pela escolástica: signum efficax gratiae - o sacramento é o sinal eficaz da graça. Essa postura sacramental mantém o nosso olhar sobre um mundo aberto; não é um olhar que vê mecanicismo, mas vê interlocução, vê o olhar de outro, palavra carregada de socorro, um olhar eficaz de outro - a sua graça, em termos teológicos. É essa eficácia que nós precisamos recuperar quando nós lemos as Escrituras.

\section{No princípio, o seio da criação e a criação de seios ${ }^{3}$}

Quando se lê as narrativas da criação no livro do Gênesis, se tem na progressão da narrativa uma dimensão que vai culminar não propriamente em Adão, mas em Eva, lá onde se diz que ela ganhou este nome por ser "mãe de todos os viventes" (Gn 3,20). É importante sublinhar esta dimensão de "seio" que cada elemento criado vem a se tornar para o que vem depois até finalmente termos o humano como "seio" - Eva. O primeiro elemento da criação é a luz, vinda diretamente do seio de

3 Sigo aqui o tema mais desenvolvido em SUSIN, Luiz Carlos. A Criação de Deus. São Paulo: Paulinas, 2003. 
Deus pela sua palavra, por sua livre e benevolente decisão. No seio da luz tudo decorre. Aqui precisamos de um parêntesis para fazer uma fenomenologia da luz, dos horizontes: na área do conhecimento, segundo a fenomenologia, embora não vejamos a luz, é ela que permite vermos tudo corretamente "na luz". É no limite dos horizontes modulados com a luz que nós temos conhecimentos. O simbolismo da luz é o maior símbolo que nós temos, desde a luz celeste até a luz da mente, conjugado frequentemente com as trevas. Mas as trevas não servem de contraposição de princípios ao estilo do dualismo zoroástrico ou maniqueu. Para quê Deus fez as trevas, a noite? Para dormir, para repousar, simplesmente. Não existem demônios na noite da criação divina; as trevas não são símbolo do mal naquele relato, alternam com o dia os tempos de trabalho e repouso. Mas a luz é o seio maior onde se fazem os céus e a terra, o dia e a noite. Céus e terra, por sua vez, vão se tornar seios também de novas criaturas como a terra seca e a água; ou os céus que terão água para descer e fecundar a terra; que por sua vez vão ser seios de animais aquáticos e animais terrestres; e que vão ganhar inclusive as ervas e grãos para alimentar animais e humanos.

O importante é ver que nesta dinâmica há uma ordem, exatamente aquela de cada criatura que está colocada ali no encadeamento e que vai se tornar seio para criatura seguintes. E finalmente aparecemos nós, feitos da fragilidade, mas também da parte moldável da terra (Adão, de adamah, da argila). Mas, finalmente, Eva, "seio de mãe". Eva é, como já anotamos, o último seio que aparece no conjunto da criação. Podemos recavar disso uma hermenêutica interessante: os humanos vão se destacando dos seios e se tornando uma quase autonomia, passados pela crise de adolescência, de transgressão, e pela assunção do princípio da realidade - a "punição" do capítulo três do Gênesis. Mas no final é a hora de voltar a ser como Eva.

Santo Agostinho disse que "Adão somos todos nós", mas ele não conseguiu dizer "Eva também somos todos nós", porque Eva tem também um "quê" de Abraão antes dele; é portadora de seio, como o próprio Abraão, o seio onde o pobre Lázaro vai ter futuro bom. Mas Eva é a culminância do humano. Inclusive no capítulo terceiro, quando oferece uma fruta tomada como transgressão para que finalmente Adão saia de sua infância feliz e sem responsabilidade, e vá viver o realismo como adulto, assumindo também sofrimento, dor, morte, trabalho, perseverança. Pode-se interpretar o terceiro capítulo do Gênesis como um capítulo de iniciação à vida adulta, graças à aliança entre aquela que veio 
auxiliar, dar força, e o mais inteligente entre os animais, as outras formas de vida. Aqui Eva tem esse papel, o de poder oferecer as condições de seio para que a humanidade se torne adulta.

\section{Ser seio para o seio: cuidadores da terra}

Agora, depois de Eva, nós temos um desafio imenso: ser seio, sermos um útero em dores de parto, para todo esse processo que foi seio para nós, agora, no ser humano se dá essa curvatura, essa virada do último que saiu do seio da criação se tornar agora seio para toda a criação. É isso que faz o humano ser humano: ele, ao destacar-se pode acolher aquilo que o acolheu. É também a maturidade do humano. É como aquele dito que se atribui a Machado de Assis: "o filho é o pai do pai". Em diversos sentidos: o filho é o pai do pai porque faz o pai ser pai; mas também porque o filho atinge sua maturidade de pai não só quando ele gera filhos, mas quando ele finalmente assume os pais como seus filhos. Há quem afirme que a nossa terra já tem sua curvatura de existência adiantada, que ela já está lá pelos seus 80 anos, numa existência que poderá ir quanto muito até os cem anos. É mãe, como dizem muitas culturas, mas bastante idosa, de qualquer forma vamos precisar cuidar dela.

Este é o desafio: redescobrir a vocação de cuidar e a responsabilidade que agora se estende até o 'sem limites'. O cuidado, como foi explorado por diversos caminhos, sobretudo na para uma ética do cuidado, na análise da literatura, no mito do cuidado, voltou com uma beleza muito grande, comentado por Heiddeger em Ser e Tempo, e mesmo na teologia do cuidado. Nós temos hoje toda uma nova linguagem para nos darmos conta de que o cuidado é uma categoria da nossa fragilidade, porque nós somos mortais, precisamos de cuidado e cuidado indica isso: a nossa mortalidade. Mas hoje é também nossa mãe terra que está clamando por cuidado. É impactante a noção de que há uma dimensão de fragilidade na terra, o que não é tão evidente à primeira vista, porque até agora nossa experiência era ao avesso, de que a Terra tudo suporta.

Existem duas maneiras de abordar etimologicamente desde nossa língua neolatina o ser humano: desde o grego e o latim. O latim homo estaria ligado a esta fragilidade; é esta situação de húmus, que é fragilidade, mas também fecundidade; é algo paradoxal; a terra mais fértil, mais fecunda é aquela em que se colocam os restos orgânicos, se fazem misturas, compostagem, e aí se tem as rosas mais belas. O homo é isto: somos humanos, somos esta compostagem. Isto é o humano no sentido 
latino. Agora no sentido grego: o antropos é aquele que, segundo a tragédia grega, rivaliza com os deuses, começa a se bater com os deuses e frequentemente acaba sendo derrotado e punido. Mas de qualquer forma é aquele que está com a face voltada para o alto, aquele que não consegue renunciar ao seu desejo de transcendência. Isso é típico do antropos. Por esse passeio pela etimologia somos ajudados a entender esta vocação: seja para reconhecer a fragilidade, de onde nós viemos, seja para reconhecer a fecundidade e a possibilidade irrefreável de transcendência.

É aqui que nós podemos ser os cuidadores da terra; e aqui está a boa notícia para a terra. As outras formas de vida na Terra, quando nós nos aproximamos delas, deveriam se alegrar, se regozijar com a nossa presença e não ter medo de nós. Esta é a diferença que aconteceu entre Adão no paraíso, que dá nome e convida os seus animais à convivência, e Noé a quem, depois de salvaguardar os animais na sua arca, Deus deu licença para caçar e comer, mas com alto preço: "sede o medo e o pavor de todos os animais..." (Gn 9,2a). Nós podemos ser o anjo da terra ou o satã da terra, como insiste Leonardo Boff, nosso ecoteólogo maior.

\section{Rahamim: dores de parto da criação}

No pensamento semítico, não existe em geral uma lógica linear, ao menos não ao modo grego e latino, em que há precedência do mais importante em título, em cabeçalho com uma introdução, depois o corpo em forma de teses numa ordem lógica até as últimas consequências. No pensamento e na narrativa semita existe mais frequentemente uma tendência circular. Por isso normalmente é no centro que se encontra o ponto alto do texto e da narrativa. É, por exemplo, o caso dos relatos sobre Abraão: todas as histórias de Abraão circulam em torno de uma narrativa central que dá coerência a todas elas. Esta narrativa central é o dilema de Abraão (cf. Gn 22): ele vai ficar com a religião dos pais sacrificando o filho ou vai dar o salto para o "não sacrifício", salvaguardando a vida que vem lá adiante na posteridade do filho, mas à custa do risco da sua própria vida? Esta é a prova dele, como Adão teve sua prova, como Caim teve sua prova, como Jesus teve sua prova. É um processo de iniciação para se tornar qualitativamente diferente.

Passamos à leitura do texto de Rm 8,18-25, que agora vai nos interessar seguindo esta estrutura circular que comentamos acima: 
${ }^{\text {A }}{ }^{18}$ Tenho para mim que os sofrimentos da presente vida não têm proporção alguma com a glória futura que nos deve ser manifestada. ${ }^{19} \mathrm{Por}$ isso, a criação aguarda ansiosamente a manifestação dos filhos de Deus. B-20 Pois a criação foi sujeita à vaidade - não voluntariamente, mas por vontade daquele que a sujeitou -, ${ }^{21}$ todavia com a esperança de ser também ela libertada do cativeiro da corrupção, para participar da gloriosa liberdade dos filhos de Deus.

${ }^{\mathrm{C}-22}$ Pois sabemos que toda a criação geme e sofre como que dores de parto até o presente dia.

${ }^{\mathrm{B} 1-{ }^{23} N a ̃ o}$ só ela, mas também nós, que temos as primícias do Espírito, gememos em nós mesmos, aguardando a adoção, a redenção do nosso corpo.

${ }^{\mathrm{A} 1-}{ }^{24}$ Porque pela esperança é que fomos salvos. Ora, ver o objeto da esperança já não é esperança; porque o que alguém vê, como é que ainda o espera? ${ }^{25}$ Nós que esperamos o que não vemos, é em paciência que o aguardamos.

É importante sublinhar esse corolário no final, o acento na paciência, porque a paciência, assim compreendida na sequência da esperança, é uma esperança que sofre, a paciência é sofrer com esperança. Por exemplo, quantos pais tem paciência com filhos adolescentes! Ora, os pais sofrem, aguentam, com esperança no crescimento dos filhos. A esperança mais profunda é uma esperança paciente, uma esperança que sofre, que aguenta com fidelidade no sofrimento.

O versículo de $\mathrm{Rm}$ 8,20 é intrigante: Quem sujeitou a criação à vaidade? Há duas possibilidades na exegese, e eventualmente podem ser complementares, não são necessariamente excludentes. Elas podem se enriquecer entre si: porque esta vaidade, este aniquilamento, esta kenosis na qual vive a criação podem ser considerados frutos do pecado humano que aniquilou o sentido da criação e jogou a criação na corrupção. E, de fato, em grande parte, a responsabilidade de nossa decisão, de nossa escolha equivocada pode estar levando o mundo à ruína, à corrupção.

Mas há uma segunda possibilidade hermenêutica, que é bem curiosa à primeira vista: o que teria levado a esta situação teria sido o desígnio do próprio criador. Ele coloca a criação em solidariedade com o sofrimento humano, inclusive com o pecado e a vaidade. Como faz com a shekiná, o simbolismo da nuvem no deserto que se inclina e vem morar, vem colocar sua tenda no meio do povo, na condição de sua fragilidade e suas errâncias. A shekinah também descansa, caminha, peregrina com o 
povo. Ela cobre o povo com sua sombra para não se torrar no sol, ela se alia ao destino e à fragilidade humana, ela se solidariza com o humano. Segundo a teologia rabínica, é uma forma muito especial da presença de Deus. Então Deus mesmo, com o povo, faz o doloroso percurso de êxodo rumo ao sábado da criação, que mais tarde iria se repetira ainda mais profundamente e dolorosamente do exílio ao santuário.

Em ambas as hipóteses, seja a ação humana corruptora, seja a ação de Deus solidário, a criação está ligada a um destino humano, como Cristo em relação a nós no sentido redentor: nós pecamos e nos extraviamos; Deus "o fez pecado por nós" - forte expressão paulina para nos redimir do pecado e nos tornar justos (cf. 2Cr 5,21). Ou seja, ele foi posto junto à nossa miséria para poder nos recuperar da miséria, a forma da solidariedade que salva.

\section{A criação como graça originária}

Mas há também, é verdade, a tese franciscana, que não se fundamenta necessariamente no pecado para termos a solidariedade tão radical de Deus. ${ }^{4}$ Duns Scotus, o "doutor sutil”, franciscano inglês que foi mestre em Paris, por exemplo, sustenta a tese da encarnação e da solidariedade independente do pecado, como um desígnio de criação em vista da consumação em Cristo. É o "primado universal de Cristo", conforme os hinos cristológicos do Novo Testamento em que se reconhece e se canta que tudo é por ele e para ele. É assim que, sem ou com pecado, somos justificados e salvos. Sempre permanece firme que Deus não age com um poder sobre nós, ele age se colocando junto de nós. Ele renuncia a uma forma de poder, a potestas de domínio, para exercer outro poder, que é o poder da solidariedade, da paciência que dá suporte, que se dá na forma de serviço.

Duns Scotus parte de uma teologia da criação em que a criação é uma demonstração da eudokia, ou seja, da benevolência, da bondade e do prazer ou graça de sua livre vontade (cf. Ef 1,5) que assim nos elegeu desde antes da criação. Trata-se de uma decisão que provém da bondade, não é uma bondade "necessária" por cima da cabeça de Deus, um fatalismo, mas uma bondade que é uma decisão, que vem da vontade e que é livre. Por isso confessamos no Credo: "Creio em um só Deus, Pai

$4 \quad$ PANCHERI Francesco Saverio; CAROL Juniper. The universal primacy of Chirst. Front Royal: Cristendom, 1984. 
onipotente, criador'. Professamos primeiro que Deus é 'Pai', e somente então que é todo-poderoso. Colocar a palavra 'poder' sem antes ter dito a palavra 'pai' é muito perigoso. Falar de Deus 'onipotente' sem antes ter dito a forma desta onipotência nos leva à crítica de Freud, em que Deus é, ao menos inconscientemente, a projeção da onipotência do nosso narcisismo, o que é altamente perigoso e danoso. Na ordem do Credo, finalmente se confessa um pai que exerce sua onipotência na forma de "criação". Assim: 1. Pai; 2. Onipotente; 3. Criador.

Duns Scotus insiste na base destas teses sobre Deus que põe sua paternidade e onipotência na criação: é a criação por amor. Ele cria também criaturas que são capazes de amar e capazes de responder a este amor. Ele não cria assim criaturas que permanecem em estado bruto. Normalmente afirmamos que a pessoa é bruta ou selvagem ou inferior quando não tem racionalidade, quando não pensa, enfim quando não é inteligente. Mas, segundo Duns Scotus, a inteligência em si tornaria o ser humano apenas um nobre animal, mas continuaria a ser bruto, um nobre bruto, mas não seria ainda humano. O que torna esta criatura um ser realmente humano não é a inteligência - e isso é um dos pontos de sua postura contra o intelectualismo na polêmica entre intelectualismo e voluntarismo da época, duas escolas, sendo a última uma característica da escola franciscana. O que, afinal, humaniza é a resposta livre, amorosa e criativa na mesma forma com que o criador amou e criou.

Existem múltiplas abordagens que são possíveis e desejáveis para elaborar uma teologia da criação. Desde a história, desde a ecologia, desde as ciências, desde a Escritura. Juntas, de forma interdisciplinar, enriquecem o nosso conhecimento. Mas mesmo depois de a ciência ter desvendado o big-bang, os buracos negros, os horizontes mais longínquos possíveis, nós continuamos ainda hoje com aquela pergunta de Leibniz, que indaga: "Por que há o ser e não simplesmente o nada?". Em outras palavras: "Porque há o universo e não o nada?" Nenhuma abordagem é exaustiva e nem todas juntas esgotam o mistério que é o universo. Aceitar o universo como um mistério é, afinal, percebê-lo de novo desde o olhar abraâmico que mais escuta do que perscruta: o universo tem uma alteridade que nós não abarcamos. A primeira e a última atitude são de reverência, e não a ordem de Descartes: "com teu cérebro torna-te senhor e possuidor do universo", exatamente assim: "maître et possesseur de l'univers". 
O universo, no fundo, é sem porquê, segundo a expressão de Angelus Silesius (†1667) um poeta e místico germânico, que diz que "a rosa é sem porque: floresce porque floresce; não cuida de si e não pergunta se alguém a vê!". A rosa subsiste em absoluta gratuidade, para além da necessidade de perguntar o porquê. É parábola do mistério do universo inteiro. Simplesmente existe, para lá de uma causa primeira e de qualquer sentido ontológico, e o único sentido do universo só pode ter na generosidade do amor a explicação, porque a inteligência não o alcança e menos ainda a ação e o domínio. O universo existe na absoluta graça de existir. Pode ser uma resposta que não satisfaça muito quem é pragmático ou racional. E o que se diz do universo, naturalmente se diz de todas as criaturas: a linguagem amorosa é o que nós temos de melhor para interpretar a criação.

A gratuidade amorosa constitui o mistério. Portanto, não é um mistério tenebroso, cheio de ameaças, mas é o oceano infinito do prazer de Deus. Pode ser interpretado como um 'absurdo' ou um 'acaso'. O acaso, na verdade, tem uma função: graças à possibilidade de acasos é que nós também temos responsabilidades; exatamente, porque sem as responsabilidades podem acontecer acasos desagradáveis e desgoverno. Porque nada está traçado necessariamente, nós temos o cuidado para com as criaturas. Temos responsabilidades e, portanto, liberdade. Se não houvessem acasos, na outra ponta teríamos somente necessidades. E se tudo fosse absolutamente necessário, nós seríamos "fantoches" de um destino; e, portanto, não haveria exercício de nossa liberdade como responsabilidade, quer a exerçamos bem ou mal. Então podemos aceitar "doses de acasos" nos quais nós somos chamados a exercer com responsabilidade a nossa liberdade - e o nosso amor generoso.

\section{O absurdo e a graça da criação ex nihilo sui et subjecti}

A ideia de absurdo surge a partir de algo que não tem causa, um efeito sem causa. A nossa ideia mais simples de absurdo é a da constatação de um fenômeno sem explicação porque não vemos ou compreendemos sua causa. Desde os gregos a "causa" é a explicação e a compreensão dos fenômenos. Ora, se não temos a causa, se não se sabe de onde veio não se pode saber como veio um fenômeno: é um absurdo. Talvez os maiores absurdos sejam os sofrimentos excessivos, que causa nenhuma dê conta. Sobretudo o sofrimento do inocente, de uma criança. Estar 
diante de um sofrimento inocente é estar diante de um fenômeno que por si dá ideia de consequência, de efeito, mas cuja causa não se pode identificar. O sofrimento inocente é o maior absurdo. Nós temos, porém, também o outro lado: algo bom e belo e alegre que existe, e cuja causa não compreendemos inteiramente. Está aí por pura gratuidade. Tem a mesma estrutura do absurdo, mas lhe damos outro nome por ser algo bom: é a mais pura graça.

No caso da criação, não há como procurar um Deus criador como sua causa, como se a criação tivesse um cordão umbilical ligado à sua causa. Se formos para trás ou para o fundo, vamos apenas chegar ao nada. Somos criaturas ex nihilo: nós viemos do nada, nem de um protoplasma originário e nem de uma coxa de um Criador ou de um ser primordial. ${ }^{5}$ Se podemos dizer que viemos de Deus, foi pela Palavra. A Palavra não é um vestígio, é a pessoa mesma em sua expressão livre e criativa. A Palavra não é uma causa pelas costas, que está na origem atrás de nós, mas é relacionamento face a face, que se dá de frente, que fez Abraão dar um passo mais à frente na direção do interlocutor. Por isso professamos que a Palavra criou e continua criando, curando, levando o universo à plenitude de desígnio que desconhecemos em sua forma de realização (Gaudium et Spes, 39). Se tentássemos examinar a criação como quem busca um cordão umbilical, verificaríamos que ele está rompido, que não há vestígios sequer que nos induzam a ir para trás. É por isso que a graça tem a mesma estrutura do absurdo: ela está aí sem explicação, sem causa, sem mérito, por pura gratuidade, e desborda na generosidade, mesmo diante do enigma das ameaças que acompanham a criação. Em outras palavras, retornando à parábola da rosa, a criação está aí com a rosa que floresce, que canta a graciosidade, mas que ao mesmo tempo pode se perder. Por isso ela evoca o cuidado, a responsabilidade e o zelo pela sua graciosidade e, eventualmente, por sua cura.

O sentido da natureza, desde os microcosmos até o macrocosmo, está intimamente conectado ao intérprete do sentido. A diferença entre o absurdo e a graça é, sobretudo, a diferença de sentido, e isso - o sentido - é decisivo na criação. Ora, nós somos, como diz Agostinho, "a boca do universo": somos aqueles que "sacerdotalmente" expressam e por isso

5 As discussões patrísticas, desde Irineu, contra a gnose, chegaram à formulação de creatio ex nihilo sui et subjecti. Em outras palavras, a criação provém de nada que seja parte de Deus ou matéria originária. 
dão sentido ao universo, orientando-o no sentido para Deus, ou então roubando e aniquilando o sentido que o universo pode ter.

Em termos práticos, para cumprir a vocação hermenêutica, sacerdotal e mediadora, o ser humano precisa conhecer a linguagem do universo. E para tanto, é necessário uma alfabetização, ou, aproveitando a expressão de Fritjof Capra, uma "ecoalfabetização". Também é preciso não só de espírito de geometria, mas espírito de fineza (Pascal), ou seja, simpatia e benevolência, bem querer, na relação com as criaturas, inclusive para sua capacidade de bem intervir. É redutivo e empobrecedor intervir só pragmaticamente, recalcando a intervenção poética, hermenêutica. A poiésis, que é uma prerrogativa humana, tem uma dimensão ética: cantar o mundo como lugar de habitação da vida, seios ecológicos cada vez mais abrangentes: seio materno, seio da casa, seio da paisagem, da ecologia, da economia, da política, do ecumenismo e, finalmente, seio do sábado em que Deus habita e repousa na criação. Quando, depois dos tempos criativos do trabalho, praticamos a dimensão sabática com a criação, nos damos conta de que Deus mesmo que está repousando conosco na criação. Pelo seio do sábado pode-se superar todo antropocentrismo que fez e faz tanto mal à criação. O ponto ômega da criação não somos nós, é o sábado. $\mathrm{E}$ o sábado significa a convivência feliz de todas as criaturas face a face.

O sentido permanece aberto e inesgotável na esperança e na paciência do bem querer, na responsabilidade e na vigilância por um mundo verdadeiramente mundo e não imundo. ${ }^{6}$ No entanto tudo é graça: a criação, que é ex nihilo, mas que é também ex plenitudine Christi, da plenitude de Cristo, é a graça originária ad extra, fonte e origem da graça de ser de todas as criaturas. A graça é originalmente graça criadora e santificadora, e historicamente é também graça sanante e redentora, mas o importante é que ela é sempre graça criadora, em dores de parto para a vida.

\section{Conclusão}

A finitude, a fragilidade e o sofrimento da criação, de toda a criação, como do ser humano, ao invés de provocar a decepção e o desespero,

6 A vocação do mundo é ser um lugar ordenado. A palavra latina mundum, ou seja, justo, em boa forma e de bom sabor, contrária de imundo, indica para a fruição da bondade, e não para o desfrute e descartabilidade. 
clamam por uma compreensão ética: compreender, no sentido de acolher como um seio amoroso acolhe quem antes de nós foi para nós um seio de nutrição. A terra enquanto nossa mãe é o paradigma de uma relação de fecundidade e de reconhecimento de que tudo é graça.

\section{Referências}

KOYRÉ, Alexandre. Do mundo fechado ao universo infinito. Rio de Janeiro; São Paulo: Forense Universitária; Edusp, 1979.

MOLTMANN, Jürgen. Deus na Criação: Doutrina ecológica da criação. Petrópolis: Vozes, 1993.

PANCHERI, Francesco Saverio; CAROL, Juniper. The universal primacy of Chirst. Front Royal: Cristendom, 1984.

SUSIN, Luiz Carlos. A Criação de Deus. São Paulo: Paulinas, 2003. . A vida dos outros: ética e teologia da libertação animal. São Paulo: Paulinas, 2015.

SUSIN, Luiz Carlos; SANTOS, Joe Marçal Gonçalves dos. Nosso planeta, nossa vida. Ecologia e Teologia. São Paulo: Paulinas, 2011. 